\title{
Thermochemistry of UC and UN
}

\author{
Guo, $\mathrm{X}^{{ }^{*}}$, Goncharov, V.G. ${ }^{1}$, Kriegsman, K.W. ${ }^{1}$, \\ White, J.T. ${ }^{2}, \mathrm{XU}, \mathrm{H}^{3}$ \\ ${ }^{1}$ Department of Chemistry, Washington State University, \\ Pullman, WA 99164, USA \\ (*Correspondance: x.guo@,wsu.edu) \\ ${ }^{2}$ Materials and Science and Technology Division, Los \\ Alamos National Laboratory, Los Alamos, NM 87545, \\ USA \\ ${ }^{3}$ Earth and Environmental Sciences Division, Los Alamos \\ National Laboratory, Los Alamos, NM 87545, USA
}

In the U.S. and many other countries, carbide and nitride matrices have received considerable attention as advanced nuclear fuel types. UC fuels are compatible with Gas-cooled Fast Reactor while UN fuels are proposed for Lead-cooled Fast Reactor applications. ${ }^{1}$ Compared to $\mathrm{UO}_{2}$, both of UC and UN have the advantages of high thermal conductivity, high melting point, and high fissile density. ${ }^{2-4}$ However, the understanding of the fuel properties of UC and UN are still limited. In this work, we focused on the thermochemical property of UC and UN with updated values and an improved methodology for future thermodynamic studies of intermetalic fuel materials.

The thermal oxidation behavior of UC and UN was studied by performing differential scanning calorimetry coupled with thermogravimetric analysis under flowing synthetic air up to $950{ }^{\circ} \mathrm{C}$. UN shows a better thermal oxidation resistance than that of UC, and with a much simpler post-oxidation route to $\mathrm{UO}_{3}$ and then gradually to $\mathrm{U}_{3} \mathrm{O}_{8-x}$. More importantly, we conducted the first high temperature oxide melt solution calorimetry on UC and UN to determine their enthalpies of formation $\left(\Delta H_{\mathrm{f}}\right)$ from elements. Previously, such methodology has been developed and applied for determining $\Delta H_{\mathrm{f}}$ of $\mathrm{U}_{3} \mathrm{Si}_{2}$, $\mathrm{USi}$, and $\mathrm{U}_{3} \mathrm{Si}_{5}{ }^{5,6}$; here we extended it to these new fuel type materials. The implication of these experimentally measrued thermochemical properties of $\mathrm{UC}$ and $\mathrm{UN}$ are two folds: $i$ ) the benchmarked $\Delta H_{\mathrm{f}}$ will enable thermodynamic modeling and DFT computation to generate new phase equilibria or optimize existing ones for $\mathrm{U}-\mathrm{C}, \mathrm{U}-\mathrm{N}$, and $\mathrm{U}-\mathrm{C}-\mathrm{N}$; and ii) a foundation can be built for future thermodynamic studies on UC-, and UNderived wastes after discharged for disposal and evaluation on their potential alteration and degradation during the interactions that can encounter in geological repositories.

1. Kuijper et al., Nucl. Eng. Des. 2006, 236, 615-634; 2. Matzke, Science of Advanced LMFBR Fuels 1986; 3. Szpunar et al., Inter. J. Nucl. Energ. 2014; 4. Zhao et al., Prog. Nucl. Energ. 2014, 71, 152-159. 5. Guo et al., J. Nucl. Mater. 2018, 507, 44-49; 6. Chung et al., J. Nucl. Mater. 2019, 523, 101110. 